\title{
The influence of socioeconomic, biogeophysical and built environment on old-age survival in a Southern European city
}

\author{
Ana Isabel Ribeiro a,b,c,d,*, Elias Teixeira Krainski ${ }^{\text {e,f,1 }}$, Roseanne Autran ${ }^{\text {g,2 }}$, Hugo Teixeira ${ }^{\text {b,c,3 }}$, \\ Marilia Sá Carvalho ${ }^{\mathrm{h}, 4}$, Maria de Fátima de Pina ${ }^{\mathrm{b}, \mathrm{c}, \mathrm{i}, \mathrm{j}, 5}$ \\ a EPIUnit-Instituto de Saúde Pública, Universidade do Porto, Portugal \\ b i3S-Instituto de Investigação e Inovação em Saúde, Universidade do Porto, Portugal \\ ${ }^{\mathrm{c}}$ INEB-Instituto de Engenharia Biomédica, Universidade do Porto, Portugal \\ d Departamento de Epidemiologia Clínica, Medicina Preditiva e Saúde Pública, Faculdade de Medicina, Universidade do Porto, Portugal \\ e Departamento de Estatística, Universidade Federal do Paraná, Curitiba, Brazil \\ ${ }^{\mathrm{f}}$ The Norwegian University for Science and Technology, Trondheim, Norway \\ ${ }^{\mathrm{g}}$ Centro de Investigação em Atividade Física, Saúde e Lazer-Faculdade de Desporto da Universidade do Porto, Portugal \\ h PROCC-Programa de Computação Científica, Fundação Oswaldo Cruz, Rio de Janeiro, Brazil

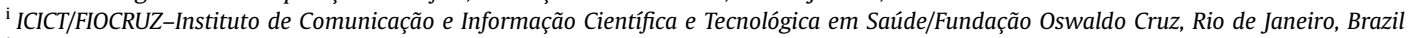 \\ ${ }^{\mathrm{j}}$ CARTO-FEN/UERJ-Departamento de Engenharia Cartográfica, Faculdade de Engenharia da Universidade do Estado do Rio de Janeiro, Brazil
}

\section{A R T I C L E I N F O}

\section{Article history:}

Received 27 February 2016

Received in revised form

15 July 2016

Accepted 9 August 2016

Available online 30 August 2016

Keywords:

Residential characteristics

Life expectancy

Climate

Socioeconomic status

Land-use

\begin{abstract}
A B S T R A C T
Old-age survival is a good indicator of population health and regional development. We evaluated the spatial distribution of old-age survival across Porto neighbourhoods and its relation with physical (biogeophysical and built) and socioeconomic factors (deprivation). Smoothed survival rates and odds ratio (OR) were estimated using Bayesian spatial models.

There were important geographical differentials in the chances of survival after 75 years of age. Socioeconomic deprivation strongly impacted old-age survival (Men: least deprived areas $\mathrm{OR}=1.31(1.05-$ $1.63)$; Women $\mathrm{OR}=1.53(1.24-1.89)$ ), explaining over $40 \%$ of the spatial variance. Walkability and biogeophysical environment were unrelated to old-age survival and also unrelated to socioeconomic deprivation, being fairly evenly distributed through the city.
\end{abstract}

(c) 2016 Elsevier Ltd. All rights reserved.

\section{Introduction}

Today, $52 \%$ of the world population, $76 \%$ of Europeans, and $63 \%$ of the Portuguese resides in urban areas (WB, 2014). For decades, urbanization was thought as synonymous with human

\footnotetext{
* Correspondence to: EPIUnit-Instituto de Saúde Pública, Universidade do Porto, Rua das Taipas 135, 4050-600 Porto, Portugal.

E-mail addresses: anaisabelribeiro@med.up.pt (A.I. Ribeiro), elias.krainski@math.ntnu.no (E.T. Krainski), roseautran@gmail.com (R. Autran), HugoTeixeira@ineb.up.pt (H. Teixeira), carvalho@fiocruz.br (M.S. Carvalho), fpina@ineb.up.pt (M.d.F. de Pina).

${ }^{1}$ Department of Mathematical Sciences-NTNU, NO-7491 Trondheim, Norway.

2 CIAFEL-Centro de Investigação em Atividade Física, Saúde e Lazer, Rua Dr. Plácido Costa, 190, 4200-450, Porto, Portugal.

${ }^{3}$ Instituto de Engenharia Biomédica-INEB, Universidade do Porto, Rua do Campo Alegre, 823, 4150-180 Porto, Portugal.

${ }^{4}$ PROCC-Programa de Computação Científica, Fundação Oswaldo Cruz, Av. Brasil, 4365 - Antiga Residência Oficial, Manguinhos, 21045-900 Rio de Janeiro, RJ, Brasil.

${ }^{5}$ ICICT/FIOCRUZ-Instituto de Comunicação e Informação Científica e Tecnológica em Saúde/Fundação Oswaldo Cruz, Av. Brasil, 4365 - Pavilhão Haiyy Moussatché, Manguinhos, 21040-900 Rio de Janeiro, RJ, Brasil.
}

development and health (Stephens, 1996). However, recent studies have shown these settings hold important inequalities and harmful exposures (Vlahov et al., 2007; WHO/UN-HABITAT, 2010).

Residential segregation by socioeconomic position, race and ethnicity, can be observed in most urban settings (Kramer and Hogue, 2009). Residential segregation refers to the spatial separation of social groups within a certain geographical area (Massey and Denton, 1988). This socio-spatial process causes important environmental differences between neighbourhoods. For instance, affluent neighbourhoods are more likely to attract health-promoting amenities, such as healthy food shops, exercise facilities, services, commerce or cultural spaces, and to exclude hazards, such as pollutant industries or heavy traffic roads (Nogueira, 2010; Stephens, 1996; Woolf and Aron, 2013). Together with socioeconomic deprivation, social fragmentation and isolation represent another negative feature of urban living. But, evidence exists that living in a walkable and mixed use neighbourhood might counteract these problems by improving social capital and by encouraging pedestrian use of streets (Hanibuchi et al., 2012; Leyden, 2003).

Urban residents are also generally exposed to poorer physical 
environments than their rural counterparts (Burkart et al., 2015; Marzluff et al., 2008; Vlahov et al., 2007) - high pollution levels, lack of natural greenspace, and frequent temperature extremes. All these influences have well-documented consequences for the health and survival of the populations (Burkart et al., 2015; Hajat et al., 2007; Shumake et al., 2013; Takano et al., 2002).

The social and environmental polarization that occurs in urban settings creates the 'perfect' circumstances to produce health inequalities between neighbourhoods in mortality and life expectancy, as numerous studies have found (Borrell et al., 2014; Diez Roux et al., 2004; Domínguez-Berjón et al., 2010; Gotsens et al., 2013; Hoffmann et al., 2014; Mari-Dell'Olmo et al., 2015). Some of these studies have also observed that, although inequalities are universal, their magnitude varies greatly from setting to setting and seem to be considerably smaller in southern European cities than in other places in Europe (Borrell et al., 2014; Gotsens et al., 2013; Hoffmann et al., 2014; Mari-Dell'Olmo et al., 2015). This is thought to be the result of differences in social pattering of health-related behaviours (Mackenbach et al., 2008; MariDell'Olmo et al., 2015) Studies that have looked at the variations in health within Portuguese urban settings have been restricted to the capital city, Lisbon (Borrell et al., 2014; Gotsens et al., 2013; Hoffmann et al., 2014; Mari-Dell'Olmo et al., 2015; Santana et al., 2015), and none of these studies have specifically addressed life expectancy and mortality of the eldest. Gains in life expectancy are currently driven by increases in old-age survival (Kannisto, 2000; Mathers et al., 2014). Therefore, old-age survival represents an important indicator of population health at the current stage of the epidemiological transition. Moreover, there are reasons to believe older populations might be particularly vulnerable to the characteristics of their immediate residential environment: climate extremes and air pollution have starker effects on the oldest (Hajat et al., 2007); older people might more frequently interact in the context of the neighbourhood; and might be more dependent on their local resources (shops, services, healthcare, recreation) (Diez Roux et al., 2004).

The fact that urban settings hold a variety of realities in a relatively small area makes them the ideal place to study and monitor health inequalities, and to implement actions against them. Moreover, because cities are human-designed places, constantly under construction, the identification of health inequalities and their causes may be able to support a health policy response by the municipal governments (Collins and Hayes, 2010).

Therefore, the aim of this study is to describe the spatial inequalities in old-age survival across the second most important urban area of Portugal, Porto, and to evaluate the role of socioeconomic and physical environmental factors in shaping those patterns. With that intent, three composite indicators will be used: the European Deprivation Index, to characterize the socioeconomic status of the neighbourhoods; the physical environmental deprivation index, to characterize biogeophysical environment (climate, pollution and greenness); and the walkability index to characterize the built environment in terms of availability and accessibility of destinations. The relations between these indicators will be explored too, so we will assess whether or not people resident in deprived areas are exposed to more detrimental physical environments.

\section{Methods}

\subsection{Study area}

Porto municipality is located in the northwest of Continental Portugal and comprised approximately 238,000 inhabitants in 2011 (INE, 2011), distributed across $41.7 \mathrm{~km}^{2}$.
Porto is limited by the Atlantic coast, and extends along the Douro River estuary. It is an industrial and port town within the Porto Metropolitan Area, the second largest metro area of Portugal with roughly 1.3 million inhabitants.

\subsection{Outcome}

Life expectancy and mortality data at old ages in Portugal are not available at neighbourhood level and even if they could be obtained estimating life expectancy for such small areas comes with well-documented problems - large standard errors and overestimation of life expectancy after 85 and 95 years of age (Eayres and Williams, 2004; Scherbov and Ediev, 2011).

Therefore, we had to derive a measure of old-age survival $\left(r_{i}=\frac{y_{i}}{n_{i}}\right)$ that expresses the probability of people aged 75-84 years surviving for an additional ten years, i.e., surpassing the average life expectancy (Ribeiro et al., 2016). Where $r_{i}$ is a ten-year survival rate, $i=1, \ldots, 109$ denotes area, the variable $y$ represents the population aged 85-94 years old in 2011 and $n$ the population aged 75-84 years old ten years before, in 2001.

\subsection{Neighbourhoods}

Population data for the above mentioned age groups was only available at census block group (CBG) level. As most covariates dated back to 2001, we used 2001 CBG as the geographical unit $(n=413$; average population of 637 inhabitants). However, due to the boundary's changes of CBG between 2001 and 2011 and the presence of areas with very few or no residents aged 85-94 years in 2011, we aggregated the areas into 109 'super' CBG, which became our final units of analysis, from now on simply referred to as neighbourhoods. This aggregation strategy meant each neighbourhood held an average of 30 and 70 inhabitants, for the age groups 85-94 and 75-84 respectively.

CBG areas were combined to form the neighbourhoods using the SKATER algorithm (Spatial 'K'luster Analysis by Tree Edge Removal) (Assunção et al., 2006), implemented in $R$ package 'spdep'(Bivand, 2015). SKATER is a regionalization approach that partitions a minimum spanning tree through a tree edge-removal procedure that focuses on edges with high dissimilarities, in this case focussing in particular upon socioeconomic deprivation differences. It allowed us to keep intact functional/natural geographical units to ensure combined areas were similar in terms of socioeconomic composition, housing typology, building style and age. This was confirmed afterwards by overlaying the new neighbourhoods with satellite imagery.

\subsection{Covariates}

\subsubsection{Socioeconomic deprivation}

The European Deprivation Index (EDI) was used to classify small areas according to their level of socioeconomic deprivation. The EDI is a transnational multivariate index developed for five European countries, France, England, Italy, Spain, and Portugal.

The EDI was constructed in three steps using both individual and area level census data. These steps are detailed elsewhere (Guillaume et al., 2015) but in brief were:

1) Construction of an individual level indicator of deprivation, based on EU-SILC (EU-Statistics on Income and Living Conditions) information;

2) Identification of variables available both at individual level (EUSILC) and at area level (2001 national population census); and

3) Determination, at individual level, whether the set of area level variables from the census selected at step 2 were associated 
with the indicators of individual deprivation created in step 1.

The associated census variables were then included in the formula of EDI. The final EDI score was based upon the weighted sum of these variables. The weights were the regression coefficients that measured the association between the indicator of individual deprivation and the variables from the census that were also available at individual level identified at step 2 .

The index was normalized and then classified into ten classes $\left(C_{1}\right.$ - least to $C_{10}$ - most deprived). Cut-offs for these theoretical deciles, were defined based on standard deviations from the overall mean, and they were then customized so that the classes included a balanced number of neighbourhoods (cut-off$\mathrm{s}=-1.28,-0.84,-0.52,-0.25,0,0.25,0.52,0.84$, and 1.28$)$. This approach avoids the well-known problems of using empirical quintiles, which assume homogeneity of risk within groups (Bennette and Vickers, 2012).

\subsubsection{Physical environment}

\subsubsection{Measure of multiple physical environmental deprivation (Porto-MEDIx)}

A measure of multiple physical environmental deprivation (Porto-MEDIx) was built for each of the 109 neighbourhoods of Porto following the principles used in the development of the nationwide Portuguese multiple physical environmental deprivation index (PT-MEDIx) (Ribeiro et al., 2015). The choice of the physical environmental variables to include in PT-MEDIX was based on an extensive literature review and was then validated by checking if the selected variables were related to health.

However, because PT-MEDIx was generated at municipality level (100 times larger than $\mathrm{CBG}$ ), the spatial resolution of the previous datasets were not adequate for creating an indicator at neighbourhood level. In addition, certain exposures included in PT-MEDIx, such as those related to the quality of the drinking water or industry proximity, are homogeneous across the city of Porto, hence irrelevant in this context.

Consequently, we generated the Porto-MEDIx, which included all the physical environmental domains covered by the nationwide version of the index, PT-MEDIx, excluding drinking water quality and industry proximity. In contrast to the national version of the index, Porto-MEDIx was developed using alternative high resolution datasets that covered the following environmental domains: air pollution (particulate matter $<10$, nitrogen dioxide, carbon monoxide), climate (mean temperature of the coldest and warmest month), and greenspace availability (NDVI, Normalized Difference Vegetation Index). Included variables and procedures are summarized in Table 1.

The neighbourhoods in the highest quintile of exposure received a score of +1 for harmful factors and -1 for beneficial factors. The Porto-MEDIx classification of each neighbourhood was the sum of these scores and, ranged from -1 (least environmental deprivation) to +2 (most). A sample calculation is shown in Table 1.

\subsubsection{Walkability index}

Neighbourhood walkability is an indicator of local accessibility and destinations. It is typically composed of four elements (Frank et al., 2010). One of these, the ratio of retail building floor areas was not possible to compute in Porto, so our index incorporated the following three variables:

- Residential density: obtained by calculating the density (number per area) of households within each neighbourhood. Data from the 2011 population and housing census was used for this purpose.

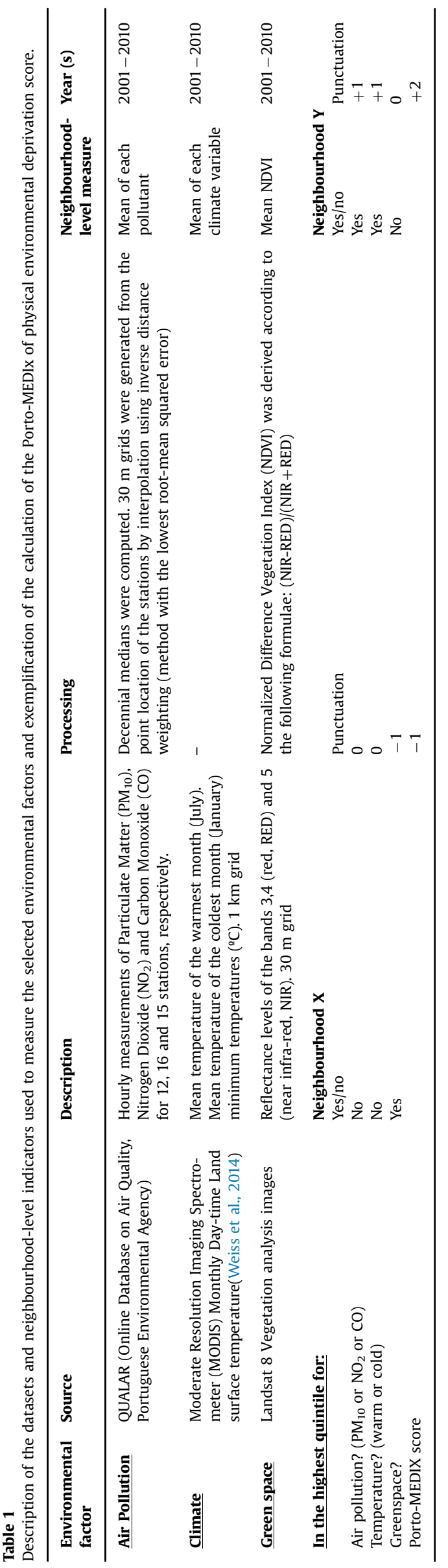


- Street connectivity: obtained by computing the density of street connection (number per area) within each neighbourhood. Only the streets that allowed pedestrian circulation were considered. Environmental Systems Research Institute, ESRI, Street map for ArcPad was used for this calculus.

- Land-use mix: obtained by computing the entropy score for each neighbourhood, with values ranging from 0 (low land use diversity) to 1 (high land use diversity). Four land uses were considered, commercial, residential, recreational, and educational. Different datasets had to be used to ascertain land-uses: 2011 census data, European Environment Agency Urban Atlas land-use map, and points of interest from ESRI Street Map for ArcPad.

Each of these variables where standardized and the walkability score was obtained by summing them (no weighting). The walkability index was then categorized in 10 classes following the approach adopted for socioeconomic deprivation.

\subsection{Statistical analysis}

To take into account the spatial autocorrelation and large variance of small areas, we used Hierarchical Bayesian spatial models. To account for the fact that the effect of each covariate class depends on the effect of the previous (ordered categorical covariate), and to allow for flexible slopes in the risk curve, flexible regression models were employed.

We assumed that the response variable, number of survivors in each area $i$ and gender $j\left(Y_{i j}\right)$, follow a Binomial distribution, where $p_{i j}$ is an unknown survival rate and $n_{i j}$ is the population aged 75-84 years old ten years before (Eq. 1).

$Y_{i j} \operatorname{Bin}\left(n_{i j}, p_{i j}\right)$

The logit of the survival rate is modelled considering gender, and the interaction between the covariates and gender $x_{i j}$ and area (Eq. 2.1).

$\operatorname{logit}\left(p_{i j}\right)=\eta_{i j}=$ gender $_{j}+f_{j}\left(x_{i}\right)+s_{i}$

Where $\eta_{i j}$ is the linear predictor, gender $_{j}$ is an intercept in the model that is specific for each gender, $f_{j}\left(x_{i}\right)$ is the gender specific effect of each covariate, which assumes the value $x_{i}$ for the area $i$, and $s_{i}$ is the area specific effect.

The function $f_{i}$ assumes a nonlinear effect of the covariates. This nonlinear effect is modelled as a first order random walk prior over the covariates' classes, that is, a normal distribution, whose mean at each class is an average over the neighbouring classes (Martino and Rue, 2009). As $x_{i}$ was categorized into classes, we can simplify $f_{j}\left(x_{i}\right)$ into $e_{l j}$, which denotes the effect of covariate class, $l$, for gender $j$.

The area specific effect $s_{i}$ was modelled considering a BYM model (Besag et al., 1991) with a parametrization suggested by Dean and colleagues (Dean et al., 2001) (Eq. 2.2.).

$s_{i}=\tau\left(\sqrt{\varphi} * u_{i}+\sqrt{1-\varphi} * v_{i}\right)$

where $u_{i}$ is the structured effect and $v_{i}$ is the unstructured effect. The $u_{i}$ effect was scaled as suggested in (Sørbye and Rue, 2014) in order to make the model more intuitive and interpretable (Riebler et al., 2016), so that $\varphi$ expresses the proportion of the spatial effect due to the structured part and $1 / \tau$ is the marginal variance of $s_{i}$. A penalised complexity prior was considered (Simpson et al., 2015).

Considering the model defined by the Eqs. (1) and (2.1), the exponential of the gender main effect is the ratio between the men's odds of survival and women's odds- the gender odds ratio (OR). Because the covariates and area specific effects were both constrained to sum-to-zero, the exponential of a specific $s_{i}$ is the ratio between the odds of survival in the area $i$ and the odds of the entire population - the area specific OR. Similarly, the exponential of $e_{l j}$ is the ratio between the odds of survival of the covariate class $l$ and gender $j$ and the overall odds for the entire population - the covariate and gender specific OR. For example, an OR of 1.10 in a certain covariate class (e.g. least socioeconomically deprived) and gender (e.g. male), means that for that gender and covariate class the odds of survival is $10 \%$ higher than the overall odds survival of the entire population of that gender. An OR would be considered significantly higher or lower if its $95 \% \mathrm{CrI}$ does not include the value 1 . Odds ratio and $95 \%$ credible intervals (95\% CrI) were derived from their posterior means and quantiles. Posterior distributions were obtained using the Integrated Nested Laplace Approximation (INLA), which was implemented in the R INLA library (Rue et al., 2009).

The model from Eq. (2.1) was our final model, but we have started with a simple model, where we included only the gender specific intercept and the spatial effect $s_{i}$, and then each covariate was successively introduced. Three different measures of goodness of fit were used (Deviance Information Criteria, Watanabe-Akaike information criterion and Conditional Predictive Ordinate) to compare models. The relative reduction in the variance of spatial effect $(\tau)$ was also evaluated to ascertain to what extent covariates contributed to explaining the spatial variation of old-age survival.

Spatial patterns were characterized using the function excursions (Bolin and Lindgren, 2015). This method uses the posterior joint distribution computed from INLA and takes into account the dependence structure, allowing the accurate identification of areas where the survival probability is greater/smaller than a certain threshold. In this study, we defined the mean old-age survival rates of each gender as the threshold. For this analysis, a simple model (with gender and spatial effect only) was used. A significance level of 0.05 was adopted.

\section{Results}

3.1. Correlation between walkability, physical environment and socioeconomic deprivation

The spatial distribution of walkability, physical environment and socioeconomic deprivation is shown in Fig. 1. We did not find signs of correlation between these covariates. There is no evidence that the biogeophysical and built environment was worst in the most deprived areas, as the correlation coefficient was near 0.02 and statistically non-significant.

\subsection{Spatial patterns and statistical modelling}

On average, in Porto, the proportion of 75-84 years old population that reached $85-94$ was $34.9 \%$ (range: $22.0-54.2$ ) among men and $45.7 \%$ (25.9-72.0) among women. These figures conceal important spatial inequalities (more than a 2.5 -fold difference in survival between areas). The spatial distribution of old-age survival is depicted in Fig. 2. Dash-lines indicate areas with significantly higher survival, and those filled with dots had significantly lower survival. In general, the areas of lower old-age survival were located in the bottom center (the old-town) and in the eastern part of the city, and those with higher old-age survival were concentrated in the western part of the city, coinciding with the patterns of socioeconomic deprivation seen in Fig. 1.

Survival rates dropped linearly as socioeconomic deprivation increased. Survival rates of the least socioeconomically deprived areas averaged $42.0 \%$ among men and $55.7 \%$ among women; in the most deprived areas these were $26.5 \%$ and $34.0 \%$ respectively. 

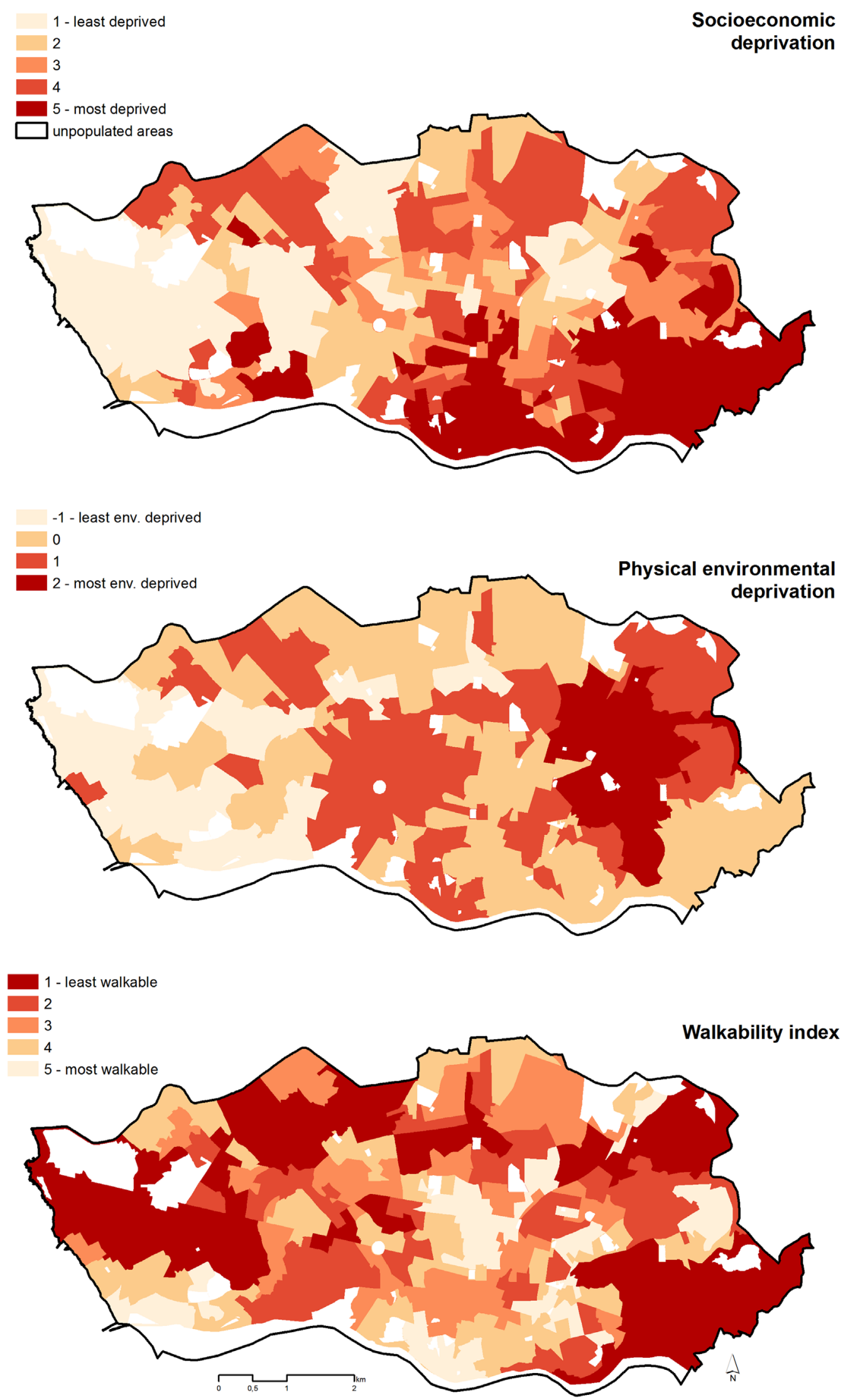

Fig. 1. Spatial distribution of the covariates socioeconomic deprivation, physical environmental deprivation and walkability index across Porto neighbourhoods. 
Survival rates $(\%)$

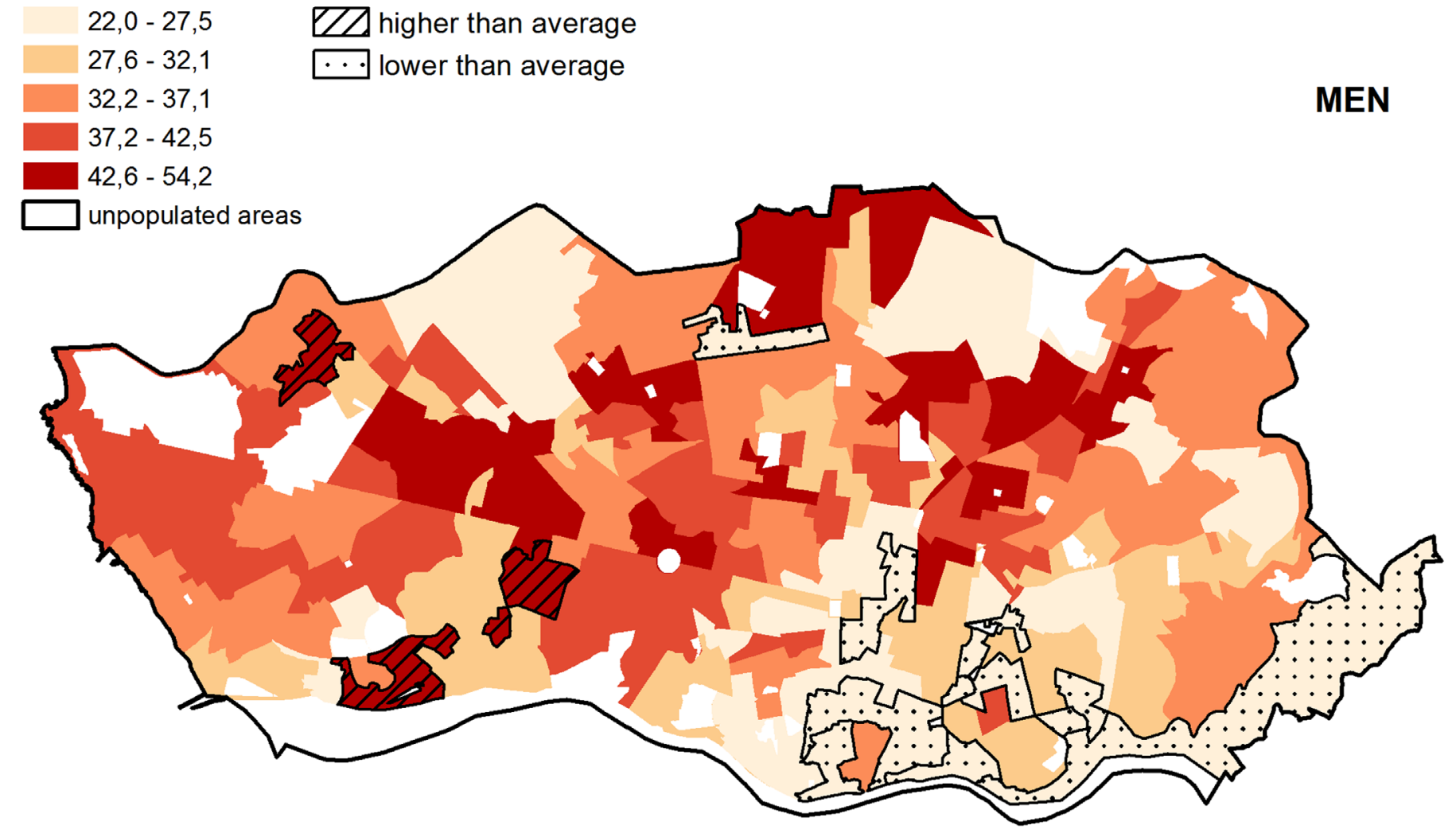

Survival rates $(\%)$

$25,9-36,0$

$36,1-41,4$

$41,5-48,2$

WOMEN

$48,3-55,1$

$55,2-72,0$

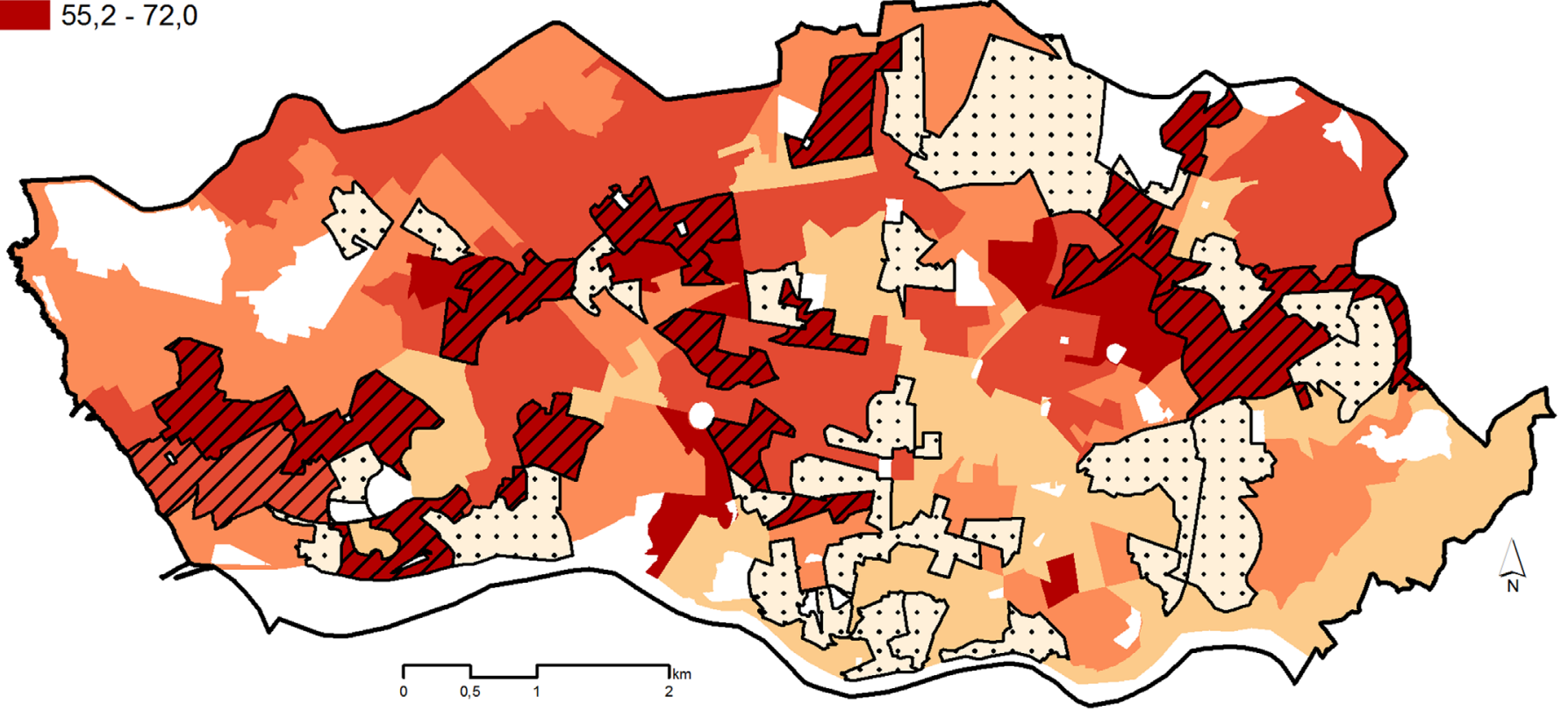

Fig. 2. Spatial distribution of the 10 -year survival rates posterior mean across Porto neighbourhoods for men and women.

Regarding the Porto-MEDIx and the walkability index, areas with poorer biogeophysical and less walkable environments had similar survival rates as those with better attributes.
Tables 2 and 3 show the RRs and corresponding 95\% CrI for the association between old-age survival and each of the covariates. There is a clear and linear relationship between old-age survival 
Table 2

Association between old-age survival, socioeconomic deprivation, physical environmental deprivation and walkability index (Men).

\begin{tabular}{|c|c|c|c|}
\hline & $\begin{array}{l}\text { Model } 1 \\
\text { OR }(95 \% \mathrm{CrI})^{\mathrm{a}} \text { (socioeconomic deprivation } \\
\text { only) }\end{array}$ & $\begin{array}{l}\text { Model } 2 \\
\text { OR (95\%CrI) (plus physical env. } \\
\text { deprivation) }\end{array}$ & $\begin{array}{l}\text { Model } 3 \\
\text { OR (95\%CrI) (plus walkability } \\
\text { index) }\end{array}$ \\
\hline \multicolumn{4}{|l|}{ Socioeconomic deprivation } \\
\hline 1 (least deprived) & $1.32(1.06-1.65)$ & $1.31(1.05-1.64)$ & $1.31(1.05-1.63)$ \\
\hline 2 & $1.24(1.05-1.45)$ & $1.23(1.04-1.44)$ & $1.23(1.04-1.44)$ \\
\hline 3 & $1.32(1.20-1.61)$ & $1.31(1.10-1.60)$ & $1.32(1.10-1.61)$ \\
\hline 4 & $1.25(1.05-1.51)$ & $1.24(1.04-1.50)$ & $1.24(1.04-1.50)$ \\
\hline 5 & $1.14(0.96-1.36)$ & $1.14(0.96-1.36)$ & $1.14(0.96-1.35)$ \\
\hline 6 & $0.93(0.78-1.11)$ & $0.94(0.78-1.11)$ & $0.94(0.78-1.11)$ \\
\hline 7 & $0.86(0.71-1.02)$ & $0.86(0.72-1.03)$ & $0.86(0.72-1.03)$ \\
\hline 8 & $0.79(0.64-0.95)$ & $0.79(0.64-0.96)$ & $0.79(0.65-0.96)$ \\
\hline 9 & $0.74(0.62-0.88)$ & $0.75(0.63-0.88)$ & $0.74(0.62-0.88)$ \\
\hline 10 (most deprived) & $0.70(0.58-0.85)$ & $0.71(0.58-0.86)$ & $0.70(0.58-0.85)$ \\
\hline \multicolumn{4}{|c|}{ Physical environmental deprivation } \\
\hline-1 (least env. deprived) & & $1.02(0.90-1.19)$ & $1.02(0.90-1.19)$ \\
\hline $\mathbf{0}$ & & $0.97(0.86-1.05)$ & $0.97(0.85-1.05)$ \\
\hline+1 & & $0.98(0.88-1.06)$ & $0.98(0.88-1.07)$ \\
\hline+2 (most env. deprived) & & $1.03(0.91-1.22)$ & $1.04(0.92-1.22)$ \\
\hline \multicolumn{4}{|l|}{ Walkability index } \\
\hline 1 (higher) & & & $0.90(0.72-1.07)$ \\
\hline 2 & & & $0.90(0.75-1.03)$ \\
\hline 3 & & & $0.96(0.84-1.09)$ \\
\hline 4 & & & $1.01(0.89-1.16)$ \\
\hline 5 & & & $1.05(0.93-1.25)$ \\
\hline 6 & & & $1.04(0.93-1.20)$ \\
\hline 7 & & & $1.03(0.90-1.18)$ \\
\hline 8 & & & $1.03(0.89-1.18)$ \\
\hline 9 & & & $1.03(0.89-1.19)$ \\
\hline 10 (lower) & & & $1.07(0.91-1.29)$ \\
\hline
\end{tabular}

In bold, statistically significant results.

a Odds ratio, OR, and corresponding 95\% Credible Intervals, 95\%CrI.

Table 3

Association between old-age survival, socioeconomic deprivation, physical environmental deprivation and walkability index (Women).

\begin{tabular}{|c|c|c|c|}
\hline & $\begin{array}{l}\text { Model } 1 \\
\text { OR }(95 \% \text { CrI })^{\text {a }} \text { (socioeconomic deprivation } \\
\text { only) }\end{array}$ & $\begin{array}{l}\text { Model } 2 \\
\text { OR (95\%CrI) (plus physical env. } \\
\text { deprivation) }\end{array}$ & $\begin{array}{l}\text { Model } 3 \\
\text { OR }(95 \% \text { CrI) (plus walkability } \\
\text { index) }\end{array}$ \\
\hline \multicolumn{4}{|l|}{ Socioeconomic deprivation } \\
\hline 1 (least deprived) & $1.55(1.26-1.92)$ & $1.53(1.25-1.90)$ & $1.53(1.24-1.89)$ \\
\hline 2 & $1.46(1.26-1.71)$ & $1.45(1.25-1.70)$ & $1.45(1.25-1.69)$ \\
\hline 3 & $1.23(1.03-1.46)$ & $1.23(1.03-1.46)$ & $1.24(1.04-1.47)$ \\
\hline 4 & $1.12(0.95-1.32)$ & $1.11(0.94-1.31)$ & $1.11(0.94-1.31)$ \\
\hline 5 & $1.04(0.88-1.21)$ & $1.04(0.88-1.21)$ & $1.03(0.88-1.21)$ \\
\hline 6 & $0.97(0.82-1.13)$ & $0.97(0.82-1.14)$ & $0.97(0.82-1.14)$ \\
\hline 7 & $0.92(0.78-1.09)$ & $0.92(0.78-1.10)$ & $0.92(0.78-1.10)$ \\
\hline 8 & $0.78(0.65-0.94)$ & $0.79(0.65-0.95)$ & $0.79(0.66-0.95)$ \\
\hline 9 & $0.70(0.60-0.82)$ & $0.71(0.60-0.83)$ & $0.71(0.60-0.83)$ \\
\hline 10 (most deprived) & $0.64(0.53-0.76)$ & $0.64(0.53-0.77)$ & $0.64(0.53-0.77)$ \\
\hline \multicolumn{4}{|c|}{ Physical environmental deprivation } \\
\hline-1 (least env. deprived) & & $1.03(0.92-1.21)$ & $1.03(0.91-1.21)$ \\
\hline $\mathbf{0}$ & & $0.97(0.86-1.04)$ & $0.96(0.86-1.04)$ \\
\hline+1 & & $0.99(0.90-1.08)$ & $1.00(0.91-1.08)$ \\
\hline+2 (most env. deprived) & & $1.01(0.89-1.16)$ & $1.02(0.89-1.17)$ \\
\hline \multicolumn{4}{|l|}{ Walkability index } \\
\hline 1 (higher) & & & $0.86(0.69-1.02)$ \\
\hline 2 & & & $0.89(0.75-1.02)$ \\
\hline 3 & & & $0.98(0.87-1.11)$ \\
\hline 4 & & & $1.02(0.92-1.18)$ \\
\hline 5 & & & $1.02(0.90-1.17)$ \\
\hline 6 & & & $1.09(0.97-1.28)$ \\
\hline 7 & & & $1.01(0.89-1.14)$ \\
\hline 8 & & & $1.02(0.89-1.14)$ \\
\hline 9 & & & $1.04(0.91-1.19)$ \\
\hline 10 (lower) & & & $1.10(0.95-1.34)$ \\
\hline
\end{tabular}

In bold, statistically significant results.

a Odds ratio, OR, and corresponding 95\% Credible Intervals, 95\%CrI. 
and socioeconomic deprivation in both genders (Men: least deprived areas $\mathrm{OR}=1.31$ (1.05-1.63); Women $\mathrm{OR}=1.53$ (1.24-1.89)). The inclusion of socioeconomic deprivation in the model explained over $41 \%$ of the spatial variability. The addition of the remaining covariates did not alter that proportion significantly and the model adjustment parameters were almost unchanged or became slightly worst. The ORs associated with the categories of Porto-MEDIx and walkability were all statistically non-significant.

\section{Discussion}

This study aimed to characterize the spatial inequalities in oldage survival in Porto, located in the second largest metropolitan area of Portugal, and to understand how socioeconomic and physical environments shape those differentials. We observed clear spatial differences, and places with survival rates significantly higher/lower than expected. More than $41 \%$ of those differences can be attributed to the socioeconomic characteristics of the neighbourhoods. The effect of socioeconomic deprivation did not seem to be mediated by environmental exposures, as no significant association between socioeconomic deprivation, physical environmental quality and walkability was observed. We also found that these measures that describe the physical environmental characteristics (built and biogeophysical) of the neighbourhoods were not associated with old-age survival at all.

In a previous study assessing spatial differentials in survival across Europe (Portugal inclusive) we found a nearly 2 -fold difference between old-age survival rates in Portugal (Ribeiro et al., 2016). Within Porto differentials were even wider (2.5- to 2.8-fold difference), which is consistent with the literature on this topic. Cities are unique settings with a high degree of residential segregation (WHO/UN-HABITAT, 2010). We were able to delimitate areas where survival rates were greater than expected through the computation of excursion sets. In general, the worst areas were located in the bottom center (the old-town) and in the eastern part of the city, and the best ones concentrated in the western part of the city. The areas of significantly lower survival matched almost perfectly the locations of social housing and of "ilhas" (meaning "islands") (Vásquez and Conceição, 2015), whereas those of higher survival occur in the most affluent neighbourhoods. "Ilhas" are a unique type of housing of working classes, comparable to the back-to-back houses in UK, and are usually of poor quality and high population density.

Socioeconomic deprivation was the main culprit underlying the observed geographical inequalities, accounting for over $41 \%$ of the spatial variability. As numerous studies and reports have highlighted, socioeconomic factors are considered the fundamental causes of health. We cannot directly compare our findings with other studies, because the outcomes, measures of risk (OR versus Relative Risk, RR) and covariates differ substantially. Still, our risk estimates are not considerably different from those reported in a series of studies on socioeconomic inequalities in all-cause (highest RR, was 1.19 in Stockholm), injury-related (1.27 in Stockholm), avoidable (circa 1.3 in Helsinki) and other cause-specific mortality (1.41 for chronic liver diseases in Stockholm) across different European metropolitan areas (Borrell et al., 2014; Gotsens et al., 2013; Hoffmann et al., 2014; Mari-Dell'Olmo et al., 2015). Specifically for cardiovascular disease mortality, Domínguez-Berjón and colleagues obtained RRs between 1.4 and 1.5 in Madrid neighbourhoods (Domínguez-Berjón et al., 2010). The Lisbon area, in Portugal, was contemplated in some of those studies, but it seems its socioeconomic gradients in mortality were rather small: RRs were generally lower than 1.1 and often statistically non-significant. It is perhaps surprising that in Lisbon, a city larger in size and holding much more diverse population groups, the effect of socioeconomic deprivation was less clear than in Porto Yet, it might reflect the fact mortality differentials are shifting to older ages (Engelman et al., 2010); previous studies dealt with overall and premature mortality, whereas ours is restricted to the eldest. The geographical units of the research conducted in Lisbon were also much larger than ours, which might conceal some socioeconomic differentials.

In contrast to what has been expected, we did not find more deprived areas to have poorer biogeophysical environments or to be less pedestrian-friendly. This provides some clues about the mechanism involved in the socio-spatial patterning of old-age survival. According to the (neo)material model (Krieger, 2001), socioeconomic factors affect health because people from lower socioeconomic strain have lower financial capacity and also tend to reside in places with fewer community resources and greater exposure to harmful environments. Our results are not fully consistent with this theory, as no sign of unfair distribution in physical environment was found. However, similar findings were reported in some other European studies, suggesting in Europe environmental injustice is not as obvious as, for instance, in the USA (Deguen and Zmirou-Navier, 2010).

We did not find any relation between our index of physical environmental deprivation and old-age survival. The comparably smaller role of physical environment compared to socioeconomic factors is evident in numerous studies and reports (DomínguezBerjón et al., 2010; Hood et al., 2015; Keon and Pépin, 2009). Porto has a relatively good access to greenspaces and exceedances of the acceptable levels of air contaminants are infrequent, which might explain their limited influence on old-age survival. On the other hand, climate extremes (heat waves and cold spells) are quite frequent in the city and can be fatal among vulnerable groups such as seniors. With this in mind, we have looked at the separate impact of climate-related variables (we also looked at the individual impact of the air pollution and greenspace), but we did not find any association (results not shown). It is plausible that good material and social conditions (housing conditions, heating) are enough to avoid the potentially harmful effects of climate extremes (Klein Rosenthal et al., 2014).

Walkable and mixed use neighbourhoods are assumed to promote social interaction and health-related behaviours such as physical activity (Hanibuchi et al., 2012; Leyden, 2003; Takano et al., 2002; Van Holle et al., 2014), which in turn might affect oldage survival (Wu et al., 2016). Despite the significant amount of positive findings, showing a beneficial effect of neighbourhood walkability, other studies have observed no link between walkability and health-related behaviours or health outcomes (Van Holle et al., 2014). Similarly, in our study, we did not find any relation between the walkability index and old-age survival. High street connectivity might also be related to traffic danger and negatively impact elderly behaviours and well-being. We have also looked at the impact of each variable that composes the walkability index separately but did not find any to be individually associated with survival (results not shown).

The main limitation of the study is related to the Modifiable Areal Unit Problem (MAUP). A different arrangement of the geographical areas could lead to different spatial patterns and relative risks. Furthermore, the areas analysed varied in population size which might affect our results and influence our ability to identify areas with significantly lower/higher survival. Excursions sets take into account the credible intervals of survival rates, which become wider as population counts decrease, so that for less populated areas it will be more difficult to reach statistical significance.

Our study was also grounded on the assumption that people have lived in the same area over the 10 year period of analysis; migration of population aged 75 years or more although infrequent remains a possibility (Evandrou et al., 2010; Wu et al., 
2015). Although there is no study of the mobility patterns and frequency among older people from Porto, evidence from crossnational studies suggest residential mobility is highly variable (Sergeant et al., 2008) and it is much less frequent in Southern European nations (ranging from 1.0 to $1.5 \%$ ) than in Western Europe (Tatsiramos, 2006). Using data from EPIPorto cohort we were able to get an approximate picture of the frequency of residential mobility in Porto. The cohort was constituted in 19992003 comprising a representative sample of 2485 adults ( $\geq 18$ years of age) residing in Porto municipality (Ramos et al., 2004). From wave 1 (1999-2003) to wave 2 (2005-2008) of the cohort, a 6 year period, $6.5 \%(n=162)$ of the participants changed their neighbourhood of residence, but this percentage was significantly lower after 75 years of age $(n=4$; mobility 2.0\%) (unpublished work). Therefore, it is unlikely that our findings are driven by residential mobility patterns. Furthermore some evidence suggests that residential mobility is most likely to cause an underestimation of spatial inequalities and socioeconomic effects (Bryere et al., 2015). Another limitation of the study, is related to the possibility that the location of nursing homes, which might have lower survival among their community residents could have influenced the analysis (Shah et al., 2013). Presence of nursing homes in particular neighbourhoods could lead to an underestimation of old age survival. However, we did not find a clear match between the locations of the areas of high and low survival and the location of Porto nursing homes. Finally, there were potentially important determinants for old-age survival we were not able to account for, namely certain physical exposures such as noise and housing conditions, and social support.

The main strength of the study is that, to our knowledge, it is the first analysing the magnitude of the old-age survival inequalities across Porto neighbourhoods, which has important public health and political consequences. Second, we used multivariate covariates, to measure the physical and socioeconomic characteristics of the neighbourhoods, whose construction was grounded on solid theory and on previously validated methods. Third, we have used robust statistical tools to identify patterns and measure associations. These methods generate smoothed estimates, avoiding random fluctuations typical of small spatial units (and populations). Frequently variables that explain variability in the response, including possible confounding variables, also vary spatially (Paciorek, 2010). Bayesian spatial models allowed us to model the spatial structure of old-age survival and reduce confounding bias resultant from any unaccounted variables. In addition, we resolved part of this potential bias by including three key multidimensional explanatory variables.

In summary, we found substantial intra-urban inequalities in the chances of survival later in life within Porto. A large share of the spatial variability was explained by the socioeconomic characteristics of the neighbourhoods. Physical environment, biogeophysical and built, were unrelated with old-age survival and did not seem to be mediating the socioeconomic effects. These findings demonstrate there is a high degree of socio-spatial segregation within Porto, suggesting the socioeconomic differentials in southern European cities might not be as small as usually thought. Policy makers should make an effort to tackle these pockets of low survival and poverty.

\section{Authors' contributions}

AIR designed the study, performed the statistical analysis and drafted the manuscript. EK performed the statistical analysis and helped to draft the manuscript. RA and HT contributed to the interpretation of results, helped to draft the manuscript and developed, together with AIR and MFP, the walkability index. MSC and
MFP supervised the research, contributed to the interpretation of results and helped to draft the manuscript. All authors read and approved the final manuscript.

\section{Acknowledgments}

This work was supported by Portuguese funds through FCT Fundação para a Ciência e a Tecnologia in the framework of project UID/BIM/04293/2013. AIR and MFP would also like to thank to FCT - Fundação para a Ciência e a Tecnologia for the grants PTDC/SAUEPI/113424/2009 and SFRH/BD/82529/2011. MSC was supported by CNpQ (309692/2013-0) and FAPERJ (E-26/203.557/2014). The authors also acknowledge Helena Tunstall for her work as language editor and the reviewers, whose numerous comments and suggestions greatly helped us to improve the article.

\section{References}

Assunção, R.M., Neves, M.C., Câmara, G., Da Costa Freitas, C., 2006. Efficient regionalization techniques for socioeconomic geographical units using minimum spanning trees. Int J. Geogr. Inf. Sci. 20, 797-811.

Bennette, C., Vickers, A., 2012. Against quantiles: categorization of continuous variables in epidemiologic research, and its discontents. BMC Med Res Method. $12(21-21)$.

Besag, J., York, J., Mollié, A., 1991. Bayesian image restoration, with two applications in spatial statistics. Ann. Inst. Stat. Math. 43, 1-20.

Bivand, R., 2015. Package ‘spdep' Spatial Dependence: Weighting Schemes, Statistics and Models. CRAN, 1-229.

Bolin, D., Lindgren, F., 2015. Excursion and contour uncertainty regions for latent Gaussian models. JRSS-Ser. B 77, 85-106.

Borrell, C., Mari-Dell'olmo, M., Palencia, L., Gotsens, M., Burstrom, B.O., DominguezBerjon, F., Rodriguez-Sanz, M., Dzurova, D., Gandarillas, A., Hoffmann, R., Kovacs, K., Marinacci, C., Martikainen, P., Pikhart, H., Corman, D., Rosicova, K., Saez, M., Santana, P., Tarkiainen, L., Puigpinos, R., Morrison, J., Pasarin, M.I., Diez, E., 2014. Socioeconomic inequalities in mortality in 16 European cities. Scand. J. Public Health 42, 245-254.

Bryere, J., Pornet, C., Dejardin, O., Launay, L., Guittet, L., Launoy, G., 2015. Correction of misclassification bias induced by the residential mobility in studies examining the link between socioeconomic environment and cancer incidence. Cancer Epidemiol. 39, 256-264.

Burkart, K., Meier, F., Schneider, A., Breitner, S., Canario, P., Alcoforado, M.J., Scherer D., Endlicher, W., 2015. Modification of Heat-Related Mortality in an Elderly Urban Population by Vegetation (Urban Green) and Proximity to Water (Urban Blue): Evidence from Lisbon, Portugal. Environ. Health Perspect.

Collins, P.A., Hayes, M.V., 2010. The role of urban municipal governments in reducing health inequities: A meta-narrative mapping analysis. Int J. Equity Health 9, 13-13.

Daniel P. Simpson, H.R., Thiago G. Martins, Andrea Riebler, Sigrunn H. Sørbye, 2015 Penalising model component complexity: A principled, practical approach to constructing priors. arXiv preprint arXiv:140346302015.

Dean, C.B., Ugarte, M.D., Militino, A.F., 2001. Detecting Interaction between Random Region and Fixed Age Effects in Disease Mapping. Biometrics 57, 197-202.

Deguen, S., Zmirou-Navier, D., 2010. Social inequalities resulting from health risks related to ambient air quality-A European review. Eur. J. Public Health 20, 27-35.

Diez Roux, A.V., Borrell, L.N., Haan, M., Jackson, S.A., Schultz, R., 2004. Neighbourhood environments and mortality in an elderly cohort: results from the cardiovascular health study. J. Epidemiol. Community Health 58, 917-923.

Domínguez-Berjón, M.F., Gandarillas, A., Segura del Pozo, J., Zorrilla, B., Soto, MJ López, L., Duque, I., Marta, M.I., Abad, I., 2010. Census tract socioeconomic and physical environment and cardiovascular mortality in the Region of Madrid (Spain). J. Epidemiol. Community Health 64, 1086-1093.

Eayres, D., Williams, E., 2004. Evaluation of methodologies for small area life expectancy estimation. J. Epidemiol. Community Health 58, 243-249.

Engelman, M., Canudas-Romo, V., Agree, E.M., 2010. The Implications of Increased Survivorship for Mortality Variation in Aging Populations. Popul Dev. Rev. 36, 511-539.

Evandrou, M., Falkingham, J., Green, M., 2010. Migration in later life: evidence from the British Household Panel Study. Population Trends - Office for National Statistics,

Frank, L.D., Sallis, J.F., Saelens, B.E., Leary, L., Cain, K., Conway, T.L., Hess, P.M., 2010. The development of a walkability index: application to the Neighborhood Quality of Life Study. Br. J. Sports Med 44, 924-933.

Gotsens, M., Mari-Dell'Olmo, M., Perez, K., Palencia, L., Martinez-Beneito, M.A. Rodriguez-Sanz, M., Burstrom, B., Costa, G., Deboosere, P., Dominguez-Berjon, F. Dzurova, D., Gandarillas, A., Hoffmann, R., Kovacs, K., Marinacci, C., Martikainen, P., Pikhart, H., Rosicova, K., Saez, M., Santana, P., Riegelnig, J., Schwierz, C., 
Tarkiainen, C., Borrell, C., 2013. Socioeconomic inequalities in injury mortality in small areas of 15 European cities. Health Place 24, 165-172.

Guillaume, E., Pornet, C., Dejardin, O., Launay, L., Lillini, R., Vercelli, M., MaríDell'Olmo, M., Fernández Fontelo, A., Borrell, C., Ribeiro, A.I., Pina, M.Fd, Mayer A., Delpierre, C., Rachet, B., Launoy, G., 2015. Development of a cross-cultural deprivation index in five European countries. J. Epidemiol. Community Health.

Hajat, S., Kovats, R.S., Lachowycz, K., 2007. Heat-related and cold-related deaths in England and Wales: who is at risk? Occup. Environ. Med 64, 93-100.

Hanibuchi, T., Kondo, K., Nakaya, T., Shirai, K., Hirai, H., Kawachi, I., 2012. Does walkable mean sociable? Neighborhood determinants of social capital among older adults in Japan. Health Place 18, 229-239.

Hoffmann, R., Borsboom, G., Saez, M., Mari Dell'Olmo, M., Burstrom, B., Corman, D., Costa, C., Deboosere, P., Dominguez-Berjon, M.F., Dzurova, D., Gandarillas, A., Gotsens, M., Kovacs, K., Mackenbach, J., Martikainen, P., Maynou, L., Morrison, J., Palencia, L., Perez, G., Pikhart, H., Rodriguez-Sanz, M., Santana, P., Saurina, C., Tarkiainen, L., Borrell, C., 2014. Social differences in avoidable mortality between small areas of 15 European cities: an ecological study. Int J. Health Geogr. 13,8 .

Hood, C.M., Gennuso, K.P., Swain, G.R., Catlin, B.B., 2015. County Health Rankings: Relationships Between Determinant Factors and Health Outcomes. Am. J. Prev. Med.

INE, 2011. Resident population (No.) by Place of residence (at the date of Census 2011), Sex and Age group; Decennial - Statistics Portugal, Population and housing census.

Kannisto, V., 2000. Measuring the compression of mortality. Demogr. Res, 3.

Keon, W.J., Pépin, L., 2009. A healthy, productive Canada: A determinant of health approach. The Standing Senate Committee on Social Affairs, Science and Technology. Final Report of Senate Subcommittee on Population Health.

Klein Rosenthal, J., Kinney, P.L., Metzger, K.B., 2014. Intra-urban vulnerability to heat-related mortality in New York City, 1997-2006. Health Place 30, 45-60.

Kramer, M.R., Hogue, C.R., 2009. Is Segregation Bad for Your Health? Epidemiol. Rev 31, 178-194.

Krieger, N., 2001. Theories for social epidemiology in the 21st century: an ecosocial perspective. Int J. Epidemiol. 30, 668-677.

Leyden, K.M., 2003. Social Capital and the Built Environment: The Importance of Walkable Neighborhoods. Am. J. Public Health 93, 1546-1551.

Mackenbach, J.P., Stirbu, I., Roskam, A.J., Schaap, M.M., Menvielle, G., Leinsalu, M. Kunst, A.E., 2008. Socioeconomic inequalities in health in 22 European countries. N Engl. J. Med 358, 2468-2481.

Mari-Dell'Olmo, M., Gotsens, M., Palencia, L., Burstrom, B., Corman, D., Costa, G., Deboosere, P., Diez, E., Dominguez-Berjon, F., Dzurova, D., Gandarillas, A., Hoffmann, R., Kovacs, K., Martikainen, P., Demaria, M., Pikhart, H., RodriguezSanz, M., Saez, M., Santana, P., Schwierz, C., Tarkiainen, L., Borrell, C., 2015. Socioeconomic inequalities in cause-specific mortality in 15 European cities. J. Epidemiol. Community Health 69, 432-441.

Martino, S., Rue, H., 2009. Implementing Approximate Bayesian Inference using Integrated Nested Laplace Approximation: a manual for the inla program. https://www.math.ntnu.no/ hrue/GMRFsim/manual.pdf.

Marzluff, J., Shulenberger, E., Endlicher, W., Alberti, M., Bradley, G., Ryan, C., Simon, U., ZumBrunnen, C., 2008. Urban Ecology. Springer, US.

Massey, D.S., Denton, N.A., 1988. The Dimensions of Residential Segregation. Soc. Forces 67, 281-315.

Mathers, C.D., Stevens, G.A., Boerma, T., White, R.A., Tobias, M.I., 2014. Causes of international increases in older age life expectancy. Lancet.

Nogueira, H.G., 2010. Deprivation amplification and health promoting resources in the context of a poor country. Soc. Sci. Med 70, 1391-1395.

Paciorek, C.J., 2010. The importance of scale for spatial-confounding bias and precision of spatial regression estimators. Stat. Sci. : a Rev. J. Inst. Math. Stat. 25, 107-125.

Ramos, E., Lopes, C., Barros, H., 2004. Investigating the effect of nonparticipation using a population-based case-control study on myocardial infarction. Ann.
Epidemiol. 14, 437-441.

Ribeiro, A.I., Krainski, E.T., Carvalho, M.S., Pina, M.F., 2016. Where do people live longer and shorter lives? An ecological study of old-age survival across 4404 small areas from 18 European countries. J. Epidemiol. Community Health.

Ribeiro, A.I., Pina, M.F., Mitchell, R., 2015. Development of a measure of multiple physical environmental deprivation. After United Kingdom and New Zealand, Portugal. Eur J Public Health.

Riebler, A., Sørbye, S.H., Simpson, D., Rue, H., 2016. An intuitive Bayesian spatial model for disease mapping that accounts for scaling. https://arxiv.org/pdf/ 1601.01180.pdf.

Rue, H., Martino, S., Lindgren, F., Simpson, D., Riebler, A., 2009. INLA: Functions which allow to perform full Bayesian analysis of latent Gaussian models using Integrated Nested Laplace Approximaxion. R Package Version.

Santana, P., Costa, C., Mari-Dell'Olmo, M., Gotsens, M., Borrell, C., 2015. Mortality, material deprivation and urbanization: exploring the social patterns of a metropolitan area. Int J. Equity Health 14, 55.

Scherbov, S., Ediev, D.M., 2011. Significance of life table estimates for small populations: Simulation-based study of estimation errors. Demogr. Res 24, 527-550.

Sergeant, J.F., Ekerdt, D.J., Chapin, R., 2008. Measurement of Late-Life Residential Relocation: Why Are Rates for Such a Manifest Event So Varied? J. Gerontol. Ser. B: Psychol. Sci. Soc. Sci. 63, S92-S98.

Shah, S.M., Carey, I.M., Harris, T., DeWilde, S., Cook, D.G., 2013. Mortality in older care home residents in England and Wales. Age Ageing 42, 209-215.

Shumake, K.L., Sacks, J.D., Lee, J.S., Johns, D.O., 2013. Susceptibility of older adults to health effects induced by ambient air pollutants regulated by the European Union and the United States. Aging Clin. Exp. Res 25, 3-8.

Sørbye, S.H., Rue, H., 2014. Scaling intrinsic Gaussian Markov random field priors in spatial modelling. Spat. Stat. 8, 39-51.

Stephens, C., 1996. Healthy cities or unhealthy islands? The health and social implications of urban inequality. Environ. Urban 8, 9-30.

Takano, T., Nakamura, K., Watanabe, M., 2002. Urban residential environments and senior citizens' longevity in megacity areas: the importance of walkable green spaces. J. Epidemiol. Community Health 56, 913-918.

Tatsiramos, K., 2006. Residential Mobility and Housing Adjustment of Older Households in Europe. IZA Discuss. Pap., 1-27.

Van Holle, V., Van Cauwenberg, J., Van Dyck, D., Deforche, B., Van de Weghe, N., De Bourdeaudhuij, I., 2014. Relationship between neighborhood walkability and older adults' physical activity: results from the Belgian Environmental Physical Activity Study in Seniors (BEPAS Seniors). Int J. Behav. Nutr. Phys. Act. 11, 110.

Vásquez, I.B., Conceição, P., 2015. Ilhas do Porto. Levantamento e Caracterização [Islands of Porto. Survey and characterization] Accessed at http://www.domussocial.pt/noticias-domus/estudo-ilhas-do-porto-consulte-aqui. Domus Social. Câmara Municipal do Porto.

Vlahov, D., Freudenberg, N., Proietti, F., Ompad, D., Quinn, A., Nandi, V., Galea, S., 2007. Urban as a Determinant of Health. J. Urban Health 84, 16-26.

WB, 2014. Urban population (\% of total). World Bank. World Bank,

Weiss, D.J., Atkinson, P.M., Bhatt, S., Mappin, B., Hay, S.I., Gething, P.W., 2014. An effective approach for gap-filling continental scale remotely sensed time-series. ISPRS J. Photo. Remote Sens 98, 106-118.

WHO/UN-HABITAT, 2010. Hidden Cities: Unmasking And Overcoming Health Inequities In Urban Settings. World Health Organization, Geneva.

Woolf, S.H., Aron, L., 2013. Physical and Social Environmental Factors, U.S. Health in International Perspective: Shorter Lives, Poorer Health. National Academies Press (US); National Research Council (US); Institute of Medicine (US), Washington (DC)

Wu, Y.-T., Prina, A.M., Barnes, L.E., Matthews, F.E., Brayne, C., 2015. Relocation at older age: results from the Cognitive Function and Ageing Study. J. Public Health (Oxf., Engl.) 37, 480-487.

Wu, Y.-T., Prina, A.M., Jones, A., Barnes, L.E., Matthews, F.E., Brayne, C., Mrc, C., 2016. Land use mix and five-year mortality in later life: Results from the Cognitive Function and Ageing Study. Health Place 38, 54-60. 